\title{
Qualidade e Composição Química da Carne de Bovinos de Corte Inteiros ou Castrados de Diferentes Grupos Genéticos Charolês x Nelore
}

\author{
Fabiano Nunes Vaz ${ }^{1}$, João Restle ${ }^{2}$, Gelson Luis Dias Feijó ${ }^{3}$, Ivan Luiz Brondani ${ }^{4}$, Joilmaro \\ Rodrigo Pereira Rosa ${ }^{5}$, Angélica Pereira dos Santos ${ }^{6}$
}

\begin{abstract}
RESUMO - Utilizaram-se 70 bovinos machos de três sistemas de acasalamento, puros Charolês (Ch) e Nelore (Ne), mestiços G1: $1 / 2 \mathrm{Ch}+1 / 2 \mathrm{Ne}(1 / 2 \mathrm{Ch})$ e $1 / 2 \mathrm{Ne}+1 / 2 \mathrm{Ch}(1 / 2 \mathrm{Ne})$ e mestiços G2: 3/4 Ch + 1/4 Ne (3/4 Ch) e 3/4 Ne + 1/4 Ch (3/4 Ne). O número de animais por grupo genético foi, respectivamente, 15, 12, 8, 12, 14 e 9 . Trinta e cinco animais foram castrados (C) aos sete meses e 35 foram mantidos inteiros (I). Os animais foram confinados dos 20 aos 24 meses, quando foram abatidos. Para avaliação da carne, foi utilizado o músculo longissimus dorsi. Não houve interação significativa entre grupo genético e estado sexual para nenhuma das variáveis estudadas. Os machos I apresentaram carne mais escura (3,05 contra 3,78 pontos) com menor marmoreio ( 4,26 contra 5,75 pontos) e menos extrato etéreo $(1,73$ contra $2,88 \%)$. Entretanto, a área de longissimus dorsi foi maior $\left(66,03\right.$ contra $\left.60,50 \mathrm{~cm}^{2}\right)$ e a carne com melhor palatabilidade, suculência e mais macia. Na comparação entre grupos genéticos, os Ch apresentaram maior longissimus dorsi. Na primeira geração de cruzamento (G1), animais $1 / 2 \mathrm{Ch}$ apresentaram maior marmoreio e teor de extrato etéreo e menor quebra à cocção que os $1 / 2 \mathrm{Ne}$. Entre os animais G2, os animais 3/4 Ne mostraram maior quebra ao descongelamento e teor de extrato etéreo na carne. Na G1, o nível de heterose chegou a $18,54 \%$ para área de longissimus dorsi, 28,10\% para teor de extrato etéreo e 64,01\% para marmoreio da carne. $\mathrm{Na} \mathrm{G} 2$, a heterose foi de $-17,37 \%$ para a textura da carne e $10,40 \%$ para área de longissimus dorsi.
\end{abstract}

Palavras-chave: bos indicus, bos taurus, castração, heterose, maciez, marmoreio

\section{Quality and Composition of Meat from Entire or Castrated Beef Cattle from Different Charolais x Nellore Genetic Groups}

\begin{abstract}
Seventy beef males of three breeding systems (BS), straightbreds Charolais (Ch) and Nellore (Ne), G1 crossbreds: $1 / 2 \mathrm{Ch}+1 / 2 \mathrm{Ne}(1 / 2 \mathrm{Ch})$ and $1 / 2 \mathrm{Ne}+1 / 2 \mathrm{Ch}(1 / 2 \mathrm{Ne})$ and $\mathrm{G} 2$ crossbreds: $3 / 4 \mathrm{Ch}+1 / 4 \mathrm{Ne}(3 / 4 \mathrm{Ch})$ and $3 / 4 \mathrm{Ne}+1 / 4 \mathrm{Ch}(3 / 4 \mathrm{Ne})$ were used. The number of animals by genetic group was, respectively, 15, 12, 8, 12, 14 and 9 . Thirty-five males were castrated (C) at seven months and 35 were kept intact (I). The animals were feedlot finished from 20 to 24 months. The longissimus dorsi muscle was used for the meat evaluation. No significant interaction was observed between genetic composition and sexual condition, for the variables studied. The I males displayed meat with darker color ( $3.05 \mathrm{vs.} 3.78$ points) with less amount of marbling (4.26 vs. 5.75 points) and less amount of ether extract (1.73 vs. $2.88 \%)$. However they presented larger (66.03 vs. $\left.60.50 \mathrm{~cm}^{2}\right)$ longissimus dorsi area and meat with better palatability, juiciness and tenderness. Ch animals had larger longissimus dorsi than the Ne. In the G1 group, the $1 / 2 \mathrm{Ch}$ meat showed larger amount of marbling and ether extract and less cooking losses than the 1/2 Ne meat. Between G2 animals, the 3/4 Ne showed meat with larger thawing losses and larger amount of ether extract. In G1 animals meat, the heterosis level reached $18.54 \%$ for longissimus dorsi area, $28.10 \%$ for ether extract and $64.01 \%$ for amount of marbling. In G2, the heterosis was $-17.30 \%$ for lean texture and $10.40 \%$ for longissimus dorsi area.
\end{abstract}

Key Words: bos indicus, bos taurus, castration, heterosis, marbling, tenderness

\section{Introdução}

Segundo VAZ et al. (1999b), a baixa lucratividade observada, atualmente, na pecuária de corte leva os produtores a procurarem alternativas que propiciem incremento na produtividade dos rebanhos. Nesse contexto, duas delas apresentam boa aceitação entre os produtores, principalmente por exigi- rem pouco investimento de capital: a utilização do cruzamento (RESTLE e VAZ, 1999) e a não castração dos machos (RESTLE et al., 1999).

No grupo das raças de corte de origem européia (Bos taurus), a Charolês é a raça continental mais criada no Rio Grande do Sul, devido às suas características de velocidade de crescimento e alto peso ao abate. Considerando-se todo o território brasileiro,

\footnotetext{
1 Zootecnista, MS., Dep. Zootecnia - UFSM, Santa Maria-RS, CEP 97105-900. E.mail: restle@ccr.ufsm.br

2 Engenheiro-Agrônomo, PhD, Prof. Titular Dep. Zootecnia - UFSM.

3 Médico Veterinário, MS, Pesquisador EMBRAPA - CNPGC.

4 Zootecnista, MS, Professor da UFSM, Aluno do curso de Doutorado/UNESP, Jaboticabal, SP.

5 Engenheiro-Agrônomo, Aluno do curso de Mestrado em Zootecnia/UFSM.

6 Aluna do curso de Zootecnia, Bolsista IC/FAPERGS.
} 
a raça Nelore (Bos indicus) é a mais criada e, nos últimos anos, tem sido uma espécie de precursora do cruzamento com as raças européias no Brasil.

Assim como as raças Bos indicus têm obtido boa aceitação no Sul, as raças Bos taurus também estão sendo bem aceitas no centro do País para o cruzamento com Nelore. Segundo KOGER (1980), a razão desse sucesso é o alto nível de heterose originária da grande distância genética existente entre os grupos Bos indicus e Bos taurus.

Apesar de a utilização de animais inteiros para o abate trazer benefícios para o produtor, devido à maior velocidade de crescimento destes em relação aos castrados (RESTLE et al., 1994; RESTLE et al., 1996a), ainda restam dúvidas com relação à qualidade da carne destes animais (MULLER e RESTLE, 1983; MORGAN et al., 1993; VAZ et al., 1999a).

O objetivo deste trabalho foi estudar o efeito do cruzamento alternado das raças Charolês e Nelore, na primeira e segunda gerações de cruzamento, assim como diferentes níveis de heterozigose sobre as características organolépticas, sensoriais e químicas da carne de bovinos de corte inteiros ou castrados, terminados aos dois anos de idade.

\section{Material e Métodos}

Este trabalho foi conduzido no Setor de Bovinocultura de Corte do Departamento de Zootecnia da Universidade Federal de Santa Maria (UFSM), localizada no município de Santa Maria, RS.

Para estudar o efeito de diferentes grupos genéticos Charolês $(\mathrm{Ch}) \mathrm{x}$ Nelore $(\mathrm{Ne})$, foram utilizados 70 animais, sendo 35 castrados a faca (C) aos sete meses de idade e 35 animais não-castrados (I), dos grupos genéticos $\mathrm{Ch}$ (sendo oito I e sete $\mathrm{C}$ ), $\mathrm{Ne}$ (cinco I e sete $\mathrm{C}), 1 / 2 \mathrm{Ch}+1 / 2 \mathrm{Ne}(1 / 2 \mathrm{Ch}$, sendo quatro I e quatro $\mathrm{C}), 1 / 2 \mathrm{Ne}+1 / 2 \mathrm{Ch}(1 / 2 \mathrm{Ne}$, sendo seis I e seis C), $3 / 4 \mathrm{Ch}+1 / 4 \mathrm{Ne}(3 / 4 \mathrm{Ch}$, sendo sete I e sete $\mathrm{C}) \mathrm{e}$ $3 / 4 \mathrm{Ne}+1 / 4 \mathrm{Ch}(3 / 4 \mathrm{Ne}$, sendo cinco I e quatro $\mathrm{C})$.

Todos esses animais eram oriundos do rebanho experimental da Universidade, nascidos na mesma época de parição. Do nascimento aos sete meses, os animais foram mantidos em campo nativo ao pé da vaca. Aos sete meses os mesmos foram desmamados e levados para o confinamento, onde receberam uma alimentação com $15 \%$ de proteína bruta, à base de silagem de sorgo e concentrado, numa relação de 70/30 (base da matéria seca) entre os mesmos. Aos 11 meses, os animais foram retirados do confinamento e levados para o campo nativo, onde permaneceram até o início da terminação em confinamento, que ocorreu quando os animais tinham 20 meses e peso médio de $285 \mathrm{~kg}$.

Durante o período de terminação em confinamento, foi fornecida uma ração contendo $12 \%$ de proteína bruta e a proporção média de volumoso/concentrado foi de 64/36 (base da matéria seca). $\mathrm{O}$ volumoso foi constituído de silagem de sorgo + cana-de-açúcar e o concentrado a base de grão de milho triturado, farelo de soja, uréia e minerais.

Após 112 dias de terminação em confinamento, o abate dos animais foi realizado em abatedouro comercial, seguindo-se o fluxo normal do estabelecimento. Após o resfriamento das carcaças por 24 horas a $0^{\circ} \mathrm{C}$, foi extraída uma amostra da carcaça direita, conforme a metodologia sugerida por MULLER (1987). Essa amostra foi dessecada e feita a separação física de músculo, gordura e osso, sendo que a porção do músculo longissimus dorsi foi embalada, identificada e congelada.

Após o congelamento, foram extraídas de cada amostra duas fatias (fatias A e B) de $2,5 \mathrm{~cm}$ e uma de $0,5 \mathrm{~cm}$ de espessura (fatia $\mathrm{C}$ ), todas obtidas perpendicularmente ao comprimento do músculo. Para cálculo das perdas ao descongelamento e cocção, foi realizada a pesagem da fatia $\mathrm{B}$, ainda congelada, depois de descongelada (antes de ser levada ao forno) e após o cozimento, que aconteceu até que a temperatura interna da fatia atingisse $70^{\circ} \mathrm{C}$. A pesagem após o cozimento foi realizada após a fatia voltar à temperatura ambiente. Após o cozimento e pesagem da fatia, foram extraídas três amostras de feixes de fibras, circulares, com $1 \mathrm{~cm}^{2}$ de área, as quais foram cortadas perpendicularmente à fibra, por meio do aparelho Warner-Bratzler Shear, que mede a resistência das fibras ao corte.

A fatia A foi descongelada e cozida juntamente com a fatia $\mathrm{B}$, sendo que, após a cocção, foi distribuída, da fatia $\mathrm{A}$, uma porção de $1 \mathrm{~cm}^{3}$ para cada um dos quatro avaliadores, os quais foram previamente treinados para atribuir valores de 1 a 9 para as características maciez, suculência e palatabilidade da carne.

Para as determinações do teor de proteína, por intermédio do método micro-Kjehdal, extrato etéreo, pelo método de Goldfish e umidade, por meio de secagem em estufa a $105^{\circ} \mathrm{C}$, foi utilizado um bife de $0,5 \mathrm{~cm}$ de espessura, retirado do músculo longissimus dorsi.

Os dados foram analisados pelo método dos quadrados mínimos (SAS, 1990), utilizando-se o seguinte modelo estatístico:

$$
\mathrm{Y}_{\mathrm{ijk}}=\mu+\mathrm{ES}_{\mathrm{i}}+\mathrm{SA}_{\mathrm{j}}+\mathrm{GG}_{\mathrm{k}: \mathrm{j}}+\mathrm{e}_{\mathrm{ijk}}
$$

em que $Y_{i j k}$ representa a observação realizada no 
n-ésimo animal, pertencente ao i-ésimo estado sexual, j-ésimo sistema de acasalamento e k-ésimo grupo genético; $\mu$, a média geral da característica; $\mathrm{ES}_{\mathrm{i}}$, o i-ésimo estado sexual; $\mathrm{SA}_{\mathrm{j}}$, o j-ésimo sistema de acasalamento; $\mathrm{CR}_{\mathrm{k}: \mathrm{j}}$, $\mathrm{k}$-ésimo grupo genético, dentro $\mathrm{j}$-ésimo sistema de acasalamento; $\mathrm{e}_{\mathrm{ijk}}$, o efeito residual realizada no n-ésimo animal.

A interação entre estado sexual e grupo genético foi inicialmente testada e removida do modelo final, por não ser significativa.

A variável sistema da acasalamento (SA) foi definida visando obter as médias ajustadas para cada característica e posterior cálculo da heterose. Assim, a variável SA apresenta três classes: puros - formada pelos animais das raças $\mathrm{Ch}$ e Ne; G1 - formada pelos animais mestiços da primeira geração de cruzamento, ou seja, os $1 / 2$ Ch e os $1 / 2 \mathrm{Ne}$; e G2 - formada pelos animais mestiços da segunda geração de cruzamento, ou seja, os 3/4 Ch e os 3/4 Ne. A comparação entre SA foi realizada pelo teste t. A heterose foi calculada pela fórmula:

$\mathrm{H} \%=[$ (média dos mestiços G1 ou G2/média dos puros ) - 1] x 100

A heterose calculada na $\mathrm{G} 1$ refere-se a individual e na G2, à total, ou seja, a soma da individual e da materna.

As comparações entre os grupos genéticos foram realizadas dentro do SA, dessa forma somente as seguintes comparações foram estudadas: Ch $v s$. Ne; 1/2 Ch vs. 1/2 Ne; e 3/4 Ch vs. 3/4 Ne.

\section{Resultados e Discussão}

Na Tabela 1 são apresentados os resultados referentes à área de longissimus dorsi, características organolépticas e quebras ao descongelamento e à cocção da carne na comparação entre animais (I) e castrados (C). Observa-se nesta Tabela que a área de longissimus dorsi foi superior nos animais I, fator que, em parte, se deve ao maior peso de carcaça dos mesmos, pois, ao ajustar-se essa medida para o peso de carcaça, a diferença deixou de existir (28,37 vs. $\left.27,77 \mathrm{~cm}^{2} ; \mathrm{P}>0,05\right)$. RESTLE et al. (1996a) observaram área de longissimus dorsi de $66,5 v s .59,2 \mathrm{~cm}^{2}$, respectivamente, para animais $\mathrm{I}$ e $\mathrm{C}$, entretanto, ao ajustar os valores para o peso de carcaça, a diferença diminuiu para $26,9 v s$. $26,0 \mathrm{~cm}^{2}$. Maior área de longissimus dorsi em animais I foi observada no trabalho de RESTLE e VAZ (1997), que, embora ressaltem a maior musculosidade da carcaça de animais I, também atribuíram ao maior peso de carcaça parte da diferença observada.
Tabela 1 - Pesos de abate e carcaça fria, espessura de gordura subcutânea, área de longissimus dorsi, características organolépticas e quebras ao descongelamento e à cocção da carne de bovinos inteiros ou castrados, de diferentes grupos genéticos Charolês x Nelore

Table 1 - Slaughter and cold carcass weights, subcutaneous fat thickness, longissimus area, color, texture, marbling, thawing and cooking losses of meat of bulls or castrated beef cattle of different Charolais $x$ Nellore genetic groups

\begin{tabular}{|c|c|c|c|}
\hline $\begin{array}{l}\text { Característica } \\
\text { Characteristic }\end{array}$ & $\begin{array}{l}\text { Castrados } \\
\text { Castrated }\end{array}$ & $\begin{array}{l}\text { Inteiros } \\
\text { Bulls }\end{array}$ & $\begin{array}{c}\text { Probabilidade } \\
\text { Probability }\end{array}$ \\
\hline $\begin{array}{l}\text { Peso de abate, } \mathrm{kg} \\
\text { Slaughter weight, } \mathrm{kg}\end{array}$ & 399 & 425 & - \\
\hline $\begin{array}{l}\text { Peso de carcaça } \\
\text { fria, kg } \\
\text { Cold carcass weight kg }\end{array}$ & 223 & 238 & - \\
\hline $\begin{array}{l}\text { Espessura de } \\
\text { gordura,mm }\end{array}$ & 4,6 & 2,5 & - \\
\hline $\begin{array}{l}\text { Fat thickness, } \mathrm{mm} \\
\text { Área de } \\
\text { longissimus, } \mathrm{cm}^{2} \\
\text { Longissimus area, } \mathrm{cm}^{2}\end{array}$ & 60,50 & 66,03 & 0,0021 \\
\hline $\begin{array}{l}\text { Área de long., } \mathrm{cm}^{2} / \\
100 \mathrm{~kg} \text { carcaça }\end{array}$ & 27,77 & 28,37 & 0,2883 \\
\hline $\begin{array}{l}\text { Long. area, } \mathrm{cm}^{2} / \\
100 \mathrm{~kg} \text { carcass weight }\end{array}$ & & & \\
\hline $\begin{array}{l}\text { Cor, pontos* } \\
\text { Color, points } *\end{array}$ & 3,78 & 3,05 & 0,0005 \\
\hline $\begin{array}{l}\text { Textura, pontos** } \\
\text { Texture, points } * *\end{array}$ & 3,44 & 3,16 & 0,1336 \\
\hline $\begin{array}{l}\text { Marmoreio, pontos*** } \\
\text { Marbling, points } * * *\end{array}$ & 5,75 & 4,26 & 0,0111 \\
\hline $\begin{array}{l}\text { Quebra ao } \\
\text { descongelamento, \% } \\
\text { Thawing loss, \% }\end{array}$ & 8,54 & 3,74 & 0,0001 \\
\hline $\begin{array}{l}\text { Quebra à cocção, \% } \\
\text { Cooking loss, \% }\end{array}$ & 30,10 & 25,45 & 0,0001 \\
\hline \multicolumn{4}{|c|}{$\begin{array}{l}\text { Variação de } 1 \text { a } 5 \text {, sendo: } 1 \text { = escura, } 3=\text { vermelha levemente } \\
\text { escura, } 5=\text { vermelha viva. } \\
\text { Variação de } 1 \text { a } 5 \text {, sendo: } 1 \text { = muito grosseira, } 5=\text { muito fina; } \\
\text { Variação de } 1 \text { a } 18 \text {, sendo: } 1-3=\text { traços, } 4-6 \text { leve. } \\
\text { Variation from } 1 \text { to } 5 \text {, being: } 1=\text { dark, } 3=\text { slightly dark red, } 5=\text { bright red. } \\
\text { Variation from } 1 \text { to } 5 \text {, being: } 1=\text { very coarse, } 5=\text { very fine. } \\
\text { Variation from } 1 \text { to } 18 \text {, being: } 1-3=\text { traces, } 4-6=\text { slight. }\end{array}$} \\
\hline
\end{tabular}

Com relação às características qualitativas da carne, observa-se na Tabela 1 que os animais $\mathrm{C}$ apresentaram carne de coloração mais clara $(\mathrm{P}<0,0005)$ que os $\mathrm{I}$. FIELD (1971) comenta que a diferença na coloração da carne entre I e C não se deve a diferenças na concentração de mioglobina no músculo, e sim à maior susceptibilidade de estresse pré-abate dos animais I, afetando o depósito de glicogênio no músculo e, posteriormente, o pH da carne. Também o marmoreio foi maior nos $\mathrm{C}$ do que nos $\mathrm{I}(\mathrm{P}<0,01)$. Maior teor de marmoreio em animais C também é reportado nos trabalhos de MULLER e RESTLE (1983) e VAZ et al. (1999a). 
Analisando-se as quebras que a carne apresentou durante o descongelamento e cocção, observa-se que animais $\mathrm{C}$ mostraram quebras maiores $(\mathrm{P}<0,0001)$ que os I, sendo de 8,54 e $30,10 \%$, respectivamente, para quebra ao descongelamento e à cocção, valores que somados indicam que, desde o descongelamento até estar cozida, a carne perdeu 38,64\% do seu peso, enquanto nos I os valores somados da quebra ao descongelamento e à cocção atingem 29,19\%.

As maiores perdas ao descongelamento e à cocção observadas nos animais $\mathrm{C}$ influenciaram diretamente a suculência da carne apresentada na Tabela 2 . Observa-se que o painel de degustadores atribuiu 6,01 de suculência para a carne de animais I e 5,41 para a carne de animais $\mathrm{C}(\mathrm{P}<0,002)$. Ainda, verifica-se que a maior suculência da carne afetou a palatabilidade. Também a maior maciez da carne dos animais I, a qual foi observada subjetivamente pelos degustadores e pela aferição da resistência das fibras ao corte (Tabela 2), deve ter influenciado a palatabilidade da carne. Em seu trabalho, VAZ (1999) verificou maiores correlações entre palatabilidade com maciez e suculência da carne.

Poucos são os trabalhos que mostram não existir diferença na maciez da carne de animais I e C

Tabela 2 - Características sensoriais, resistência das fibras ao corte e características químicas da carne de bovinos inteiros ou castrados, de diferentes grupos genéticos Charolês $x$ Nelore

Table 2 - Sensorial characteristics, shear force and chemical characteristics of meat of bulls or castrated beef cattle of different Charolais $x$ Nellore genetic groups

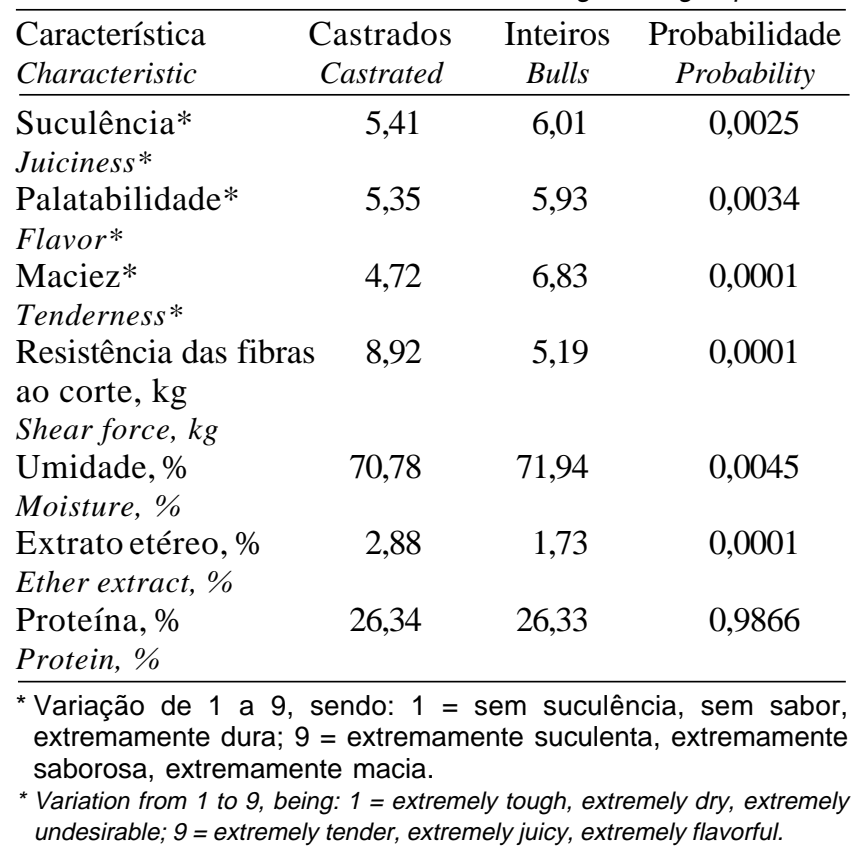

(SEIDEMAN et al., 1982; GERRARD et al., 1987) e quase inexistentes aqueles que indicam carne mais macia em animais I, ainda assim quando ocorrem, referem-se a animais abatidos com idade de até quatorze meses (VAZ et al., 1999a). O fato é que a grande maioria dos trabalhos que estudaram animais I e C mostra carne menos macia em animais I (MULLER e RESTLE, 1983; RESTLE et al., 1996a). Para WHEELER et al. (1990), isso é reflexo da maior concentração de calpastatina no músculo de animais I. A atuação da calpastatina é na forma de inibição das enzimas proteolíticas cálcio dependentes (CDP I e CDP II).

GERRARD et al. (1987) explicam que existe interação entre estado sexual e idade ao abate influenciando na maciez da carne. Esses autores constataram em seu trabalho que os animais $\mathrm{C}$ apresentaram decréscimo contínuo na maciez da carne com o incremento da idade, enquanto nos animais I houve grandes oscilações com o incremento da idade, com menores valores de força de cizalhamento aos 12 e 18 meses de idade. Os autores teorizam que a grande variabilidade ocorrida nos I em todas as idades pode ser atribuída ao rápido ciclo de crescimento como causa do incremento da síntese e degradação rápida do colágeno, que pode estar imaturo e passar por diferentes incrementos na maturação em tempos de amostragem distintos, o que acarretaria na variação ocorrida na maciez da carne de animais I.

Outra possível explicação para a maior maciez da carne dos animais I pode ser devido à susceptibilidade ao estresse pré-abate e produção de carne tipo "DFD" (do inglês "dark, firm and dry", ou seja, escura, consistente e não exsudativa), já que se observa na Tabela 1 que a carne de animais I apresentou maior retenção de água e foi mais escura. LAWRIE (1970) explica que carnes tipo "DFD" com pH acima de 5,8 costumam ser mais macias que as normais. Nos animais do presente trabalho, notou-se, nos últimos dias de experimento, que os animais inteiros eram mais dóceis que os castrados, o que também foi constatado no frigorífico, no momento pré-abate, tendo proporcionado menor estresse antes da insensibilização dos animais.

Analisando-se a composição química da carne (Tabela 2), a maior capacidade de retenção de água da carne dos animais inteiros pode ser confirmada, pois, mesmo apresentando maior teor de umidade $(\mathrm{P}<0,0045)$, esta não foi liberada quando foi descongelada e cozida (Tabela 1). 


\section{Rev. bras. zootec.}

$\mathrm{Na}$ Tabela 2, ainda com relação à composição química da carne, observa-se que animais $\mathrm{C}$, assim como mais marmoreio (Tabela 1), também apresentaram maior conteúdo de extrato etéreo no músculo, o que também foi verificado por CHAMAPGNE et al. (1969). Vários outros trabalhos constataram que animais I apresentam carcaças mais magras (MULLER e RESTLE, 1983; RESTLE et al., 1994; RESTLE et al., 1996a; RESTLE e VAZ, 1997; VAZ et al., 1999a).

$\mathrm{O}$ maior teor de marmoreio e extrato etéreo no músculo não resultou em melhor palatabilidade da carne. VAZ (1999) cita que o conceito geral de que carnes com maior conteúdo de gordura apresentam melhor palatabilidade não deve ser generalizado. $\mathrm{O}$ referido autor verificou em seu trabalho que o coeficiente de correlação entre suculência e palatabilidade foi praticamente o dobro $(\mathrm{r}=0,40)$ daquele verificado entre marmoreio e palatabilidade $(\mathrm{r}=0,21)$.

Com relação aos grupos genéticos estudados, observa-se na Tabela 3 que, na comparação entre os animais puros, somente houve diferença na área de Longissimus dorsi, que foi maior $(\mathrm{P}<0,05)$ nos animais $\mathrm{Ch}$. Similaridade nas características qualitativas da carne de Ch e Ne também foi constatada por
MOLETTA e RESTLE (1996a), em confinamento de animais desses dois grupos genéticos e que foram abatidos aos 26 meses. Na comparação entre os animais da G1, existiu diferença no teor de marmoreio, que foi maior nos animais $1 / 2 \mathrm{Ch}(8,00 \mathrm{vs} .5,58)$. Em seu trabalho, MARSHALL et al. (1987) também mostraram diferença entre as cruzas recíprocas da G1 nesta característica, com valores de 5,04 e 4,06, respectivamente, para novilhos 1/2 Pardo Suíço + 1/2 Aberdeen e 1/2 Aberdeen + 1/2 Pardo Suíço. Segundo MARSHALL et al. (1987), essa diferença pode ser atribuída a maior desenvolvimento dos novilhos amamentados por vacas de genótipos com melhor produção leiteira, resultando em um acúmulo de gordura intramuscular durante o período em que o animal recebe alto aporte energético, e esse efeito seria refletido mais tarde na carcaça do animal.

Durante a fase de terminação, observou-se que o ganho de peso médio diário dos animais foi de $1,17 \mathrm{e}$ $0,93 \mathrm{~kg}$, respectivamente, para $\mathrm{Ch}$ e $\mathrm{Ne}, 1,27 \mathrm{~kg}$ nos $1 / 2$ Ch e $1,12 \mathrm{~kg} \operatorname{nos} 1 / 2 \mathrm{Ne}$, e $1,25 \mathrm{~kg} \operatorname{nos} 3 / 4 \mathrm{Ch}$, enquanto os 3/4 $\mathrm{Ne}$ ganharam $1,09 \mathrm{~kg}$.

Animais $1 / 2 \mathrm{Ch}$ apresentaram menor quebra ao cozimento da carne que os $1 / 2 \mathrm{Ne}$ (Tabela 3). Já na

Tabela 3 - Área de Longissimus dorsi (ALD), ALD/100 kg de carcaça (ALA), cor, textura (TEX), marmoreio (MAR), quebra ao descongelamento (QD) e à cocção $(\mathrm{QC})$ da carne de bovinos inteiros ou castrados, de diferentes grupos genéticos Charolês (Ch) x Nelore (Ne)

Table 3 - Longissimus area (ALD), ALD/100 kg carcass weight (ALA), color (COR), texture (TEX), marbling (MAR), thawing (QDE) and cooking losses (QCO) of meat of entire or castrated beef cattle of different Charolais (Ch) $x$ Nellore (Ne) genetic groups

\begin{tabular}{|c|c|c|c|c|c|c|c|}
\hline $\begin{array}{l}\text { Grupo genético } \\
\text { Genetic group }\end{array}$ & $\mathrm{ALD}, \mathrm{cm}^{2}$ & $\mathrm{ALA}, \mathrm{cm}^{2}$ & COR & TEX & MAR & QDE, \% & $\mathrm{QCO}, \%$ \\
\hline $\mathrm{Ch}$ & $63,1^{\mathrm{a}}$ & 29,0 & 3,62 & 3,74 & 3,98 & 5,47 & 28,6 \\
\hline $\mathrm{Ne}$ & $52,2^{\mathrm{b}}$ & 27,7 & 3,52 & 3,39 & 4,29 & 6,83 & 29,3 \\
\hline Média puros & $57,7^{\mathrm{C}}$ & 28,4 & 3,57 & $3,57^{\mathrm{A}}$ & $4,14^{\mathrm{B}}$ & 6,15 & 28,9 \\
\hline \multicolumn{8}{|l|}{ Straigthbreds mean } \\
\hline $1 / 2 \mathrm{Ch}$ & 68,4 & 28,1 & 3,50 & 3,50 & $8,00^{\mathrm{c}}$ & 4,74 & $24,9 d$ \\
\hline $1 / 2 \mathrm{Ne}$ & 68,4 & 27,6 & 3,42 & 3,25 & $5,58^{d}$ & 6,81 & $28,6 \mathrm{c}$ \\
\hline Média cruzados G1 & $68,4^{\mathrm{A}}$ & 27,8 & 3,46 & $3,38^{\mathrm{AB}}$ & $6,79^{\mathrm{A}}$ & 5,78 & 26,8 \\
\hline \multicolumn{8}{|l|}{ G1 crossbreds mean } \\
\hline Heterose G1, \% & 18,54 & $-2,11$ & $-3,08$ & $-5,32$ & 64,01 & $-6,02$ & $-7,27$ \\
\hline \multicolumn{8}{|l|}{ G1 heterosis, \% } \\
\hline 3/4 Ch & 62,7 & 27,3 & 3,29 & 3,00 & 3,64 & $5,03 \mathrm{f}$ & 27,8 \\
\hline $3 / 4 \mathrm{Ne}$ & 64,7 & 28,7 & 3,15 & 2,90 & 4,53 & $7,97 \mathrm{e}$ & 27,4 \\
\hline Média cruzados G2 & $63,7^{\mathrm{B}}$ & 28,0 & 3,22 & $2,95^{\mathrm{B}}$ & $4,08^{\mathrm{B}}$ & 6,50 & 27,6 \\
\hline G2 crossbreds mean & & & & & & & \\
\hline Heterose G2, \% & 10,40 & $-1,41$ & $-9,80$ & $-17,37$ & $-1,45$ & 5,69 & $-4,50$ \\
\hline
\end{tabular}

Médias, na coluna, seguidas por letras minúsculas diferentes, na comparação entre Ch e Ne, ou entre 1/2 Ch e 1/2 Ne, ou entre 3/4 Ch e 3/4 Ne, são diferentes $(\mathrm{P}<0,05)$ pelo teste $t$.

Médias, na coluna, seguidas por letras maiúsculas diferentes, na comparação entre puros e cruzados G1 e G2, são diferentes (P<0,05) pelo teste $\mathrm{t}$.

Means, within a column, followed by small different letters for the comparison between Ch and Nellore, or between 1/2 Ch and 1/2 Ne, or between 3/4 Ch and 3/4 Ne, are different $(P<.05)$ by $t$ test.

Means, within a column, followed by capital different letters for the comparison among strightbreds and G1 and G2 crossbreds, are different ( $P<.05)$ by $t$ test. 
G2, os animais e 3/4 Ne apresentaram maior perda ao descongelamento. Utilizando animais abatidos aos 14 meses, FLORES (1997) e RESTLE et al. (1997b) observaram que, em novilhos cruzados Ne x Hereford, o incremento de Ne no genótipo aumentou a quebra ao descongelamento, fazendo com que a suculência da carne decrescesse. Trabalhando com animais de quatorze meses $3 / 4 \mathrm{Ch}+1 / 4 \mathrm{Ne}$ ou $3 / 4$ Hereford + $1 / 4 \mathrm{Ne}$, ROCHA et al. (1997) verificaram que os mestiços $\mathrm{Ch}$ apresentaram carne com menor quebra ao cozimento.

Ainda com referência às características apresentadas na Tabela 3, observa-se que, na comparação entre os SA, a heterose foi significativa para área de Longissimus dorsi na G1 (18,54\%) e na G2 (10,40\%), para marmoreio na G1 $(64,01 \%)$ e para textura da carne na G2 $(-17,37 \%)$. Altos valores de heterose para marmoreio também foram verificados por MARSHALL et al. (1987), ao pesquisarem novilhos Aberdeen e Pardo Suíço, observando 24,9\% de heterose nessa característica. Trabalhando com animais $\mathrm{Ch}, \mathrm{Ne}$ e suas cruzas $\mathrm{F}_{1}$, abatidos aos 24 meses de idade, RESTLE et al. (1995a,b) observaram que para espessura de gordura a heterose foi de $4,58 \% \mathrm{e}$ para marmoreio de $24,35 \%$.

Na comparação entre os animais G1, observa-se que o maior marmoreio da carne dos animais $1 / 2 \mathrm{Ch}$ também foi refletido em maior $(\mathrm{P}<0,05)$ teor de extrato etéreo (Tabela 4). O extrato etéreo também foi maior nos animais $3 / 4 \mathrm{Ne}$, quando comparados com o outro grupo genético da G2 (3/4 Ch). Trabalhando com vacas de descarte, PEROBELLI et al. (1994) verificaram que o acabamento e a porcentagem de gordura foram inferiores nas vacas $\mathrm{Ch}$ em relação as vacas Ne. Carcaça mais magra em animais Ch e suas cruzas são verificados nos trabalhos de LUCHIARI FILHO et al. (1989), DeROUEN et al. (1992), MOLETTA e RESTLE (1996b) e WHEELER et al. (1996).

A menor deposição de gordura em animais $\mathrm{Ch}$ abatidos aos dois anos de idade deve-se, provavelmente, ao fato que, a essa idade, os animais ainda apresentam crescimento muscular, pois BARBER et al. (1981), estudando o comportamento da raça Ch com respeito ao seu acabamento em comparação a novilhos de uma raça considerada mais precoce em deposição de gordura (Aberdeen), não verificaram diferença no grau de acabamento dos animais, quando

Tabela 4 - Suculência (SUC), palatabilidade (PAL), maciez (MAC), resistência das fibras ao corte (RFC), umidade (UMI), extrato etéreo (EXT) e proteína (PRO) da carne de bovinos inteiros ou castrados, de diferentes grupos genéticos Charolês (Ch) $x$ Nelore $(\mathrm{Ne})$

Table 4 - Juiciness (SUC), flavor (PAL), tenderness (MAC), shear force (RFC), moisture (UMI), ether extract (EXT) and protein (PRO) of meat of entire or castrated beef cattle of different Charolais (Ch) $x$ Nellore (Ne) genetic groups

\begin{tabular}{|c|c|c|c|c|c|c|c|}
\hline $\begin{array}{l}\text { Característica } \\
\text { Characteristic } \\
\end{array}$ & SUC & PAL & MAC & $\mathrm{RFC}, \mathrm{kg}$ & UMI, \% & EXT, \% & PRO, \% \\
\hline $\mathrm{Ch}$ & 5,58 & 5,70 & 6,19 & 6,97 & $72,7^{\mathrm{a}}$ & 1,97 & 25,3 \\
\hline $\mathrm{Ne}$ & 5,71 & 5,37 & 5,22 & 7,70 & $71,3^{\mathrm{b}}$ & 2,23 & 26,4 \\
\hline Média puros & 5,64 & 5,53 & 5,70 & 7,33 & $72,0^{\mathrm{A}}$ & $2,10^{\mathrm{B}}$ & 25,9 \\
\hline \multicolumn{8}{|l|}{ Straigthbreds mean } \\
\hline $1 / 2 \mathrm{Ch}$ & 5,79 & 5,66 & 5,71 & 6,37 & $69,3^{\mathrm{d}}$ & $3,19^{c}$ & 27,5 \\
\hline $1 / 2 \mathrm{Ne}$ & 5,68 & 5,70 & 6,04 & 7,20 & $71,6^{\mathrm{c}}$ & $2,18^{d}$ & 26,2 \\
\hline Média cruzados G1 & 5,73 & 5,68 & 5,87 & 6,79 & $70,4^{\mathrm{B}}$ & $2,69^{\mathrm{A}}$ & 26,9 \\
\hline \multicolumn{8}{|l|}{ G1 crossbreds mean } \\
\hline Heterose G1, \% & 1,59 & 2,71 & 2,98 & $-7,37$ & $-2,22$ & 28,10 & 3,86 \\
\hline \multicolumn{8}{|l|}{ Glheterosis, \% } \\
\hline $3 / 4 \mathrm{Ch}$ & 5,59 & 5,63 & 6,01 & 6,44 & 72,3 & $1,74^{\mathrm{f}}$ & 26,0 \\
\hline $3 / 4 \mathrm{Ne}$ & 5,92 & 5,80 & 5,48 & 7,65 & 70,9 & $2,52^{\mathrm{e}}$ & 26,6 \\
\hline Média cruzados G2 & 5,75 & 5,72 & 5,74 & 7,04 & $71,6^{\mathrm{A}}$ & $2,13^{\mathrm{B}}$ & 26,3 \\
\hline G2 crossbreds mean & & & & & & & \\
\hline Heterose G2, \% & 1,95 & 3,44 & 0,70 & $-3,96$ & $-0,56$ & 1,43 & 1,54 \\
\hline
\end{tabular}

Médias, na coluna, seguidas por letras minúsculas diferentes, na comparação entre Ch e Ne, ou entre 1/2 Ch e 1/2 Ne, ou entre 3/4 Ch e 3/4 $\mathrm{Ne}$, são diferentes $(\mathrm{P}<0,05)$ pelo teste $t$.

Médias, na coluna, seguidas por letras maiúsculas diferentes, na comparação entre puros e cruzados $\mathrm{G} 1$ e $\mathrm{G} 2$, são diferentes (P<0,05) pelo teste t.

Means, within a column, followed by small different letters for the comparision between Ch and Nellore, or between 1/2 Ch and 1/2 Ne, or between 3/4 Ch and 3/4 Ne, are different $(P<.05)$ by $t$ test.

Means, within a column, followed by capital different letters for the comparision among strightbreds and G1 and G2 crossbreds, are different (P<.05) by $t$ test. 
524 Rev. bras. zootec.

se permitiu que o Ch atingisse o seu peso adulto. Ao estudarem diferentes pesos de abate para novilhos $\mathrm{Ch}$, RESTLE et al. (1996b, 1997a) verificaram que os animais $\mathrm{Ch}$ atingiram 5,4 $\mathrm{mm}$ de espessura de gordura aos $495 \mathrm{~kg}$, após 184 dias de terminação.

\section{Conclusões}

Animais inteiros apresentaram carne macia, com boa palatabilidade e suculência e menores teores de extrato etéreo.

Entre animais Charolês e Nelore não houve diferenças nas características sensoriais. Nas características químicas observou-se diferença apenas no teor de umidade da carne.

$\mathrm{O}$ cruzamento entre as raças Charolês e Nelore produziu animais $\mathrm{F}_{1}$ com alto grau de marmoreio na carne.

Genótipos com maior porcentagem de Charolês no cruzamento apresentaram menores teores de extrato etéreo que aqueles com maior porcentagem de Nelore.

\section{Referências Bibliográficas}

BARBER, K.A., WILSON, L.L., ZIEGLER, J.H. et al. 1981. Charolais and Angus steers slaughtered at equal percentages of mature cow weight. I. Effects of slaughter weight and energy density on carcass traits. J. Anim. Sci., 52(2):218-231.

CHAMPAGNE, J.R., CARPENTER, J.W., HENTGES JR., J.F. et al. 1969. Fedlot performance and carcass characteristics of young bulls and steers castrated at four ages. J. Anim. Sci., 29(6):887-890.

DeROUEN, S.M., FRANKE, D.E., BIDNER, T.D. et al. 1992. Two- Three-, and four-breed rotational crossbreeding of beef cattle: carcass traits. J. Anim. Sci., 70(12):3665-76.

FIELD, R.A. 1971. Effect of castration on meat quality and quantity. J. Anim. Sci., 32(5):849:858.

FLORES, J.L.C. Desempenho em confinamento e características de carcaça e da carne de bovinos de diferentes grupos genéticos abatidos aos quatorze meses. Santa Maria, RS: UFSM, 1997, 109p. Dissertação (Mestrado em Zootecnia) - Universidade Federal de Santa Maria, 1997.

GERRARD, D.E., JONES, S.J., ABERLE, E.D. et al. 1987. Collagen stability, testosteronesecretion and meat tenderness in growing bulls and steers. J. Anim. Sci., 65(5):1236-42.

KOGER, M. Effective crossbreeding systems utilizing zebu cattle. 1980. J. Anim. Sci., 50(6):1213-20.

LAWRIE, R.A. 1970. Ciência de la carne. Zaragoza: Acribia. $342 p$.

LUCHIARI FILHO, A., LEME, P.R., RAZOOK, A.G. et al. 1989. Características de carcaça e rendimento de porção comestível de machos Nelore comparados a cruzados $\left(\mathrm{F}_{1}\right)$ obtidos do acasalamento de touros das raças Canchim, Santa Gertrudis, Caracu, Holandês e Suiço com fêmeas Nelore. II. Animais castrados terminados a pasto. Bol. Ind. Anim., 46(1):27-35.

MARSHALL, T.T., HARGROVE, D.D., OLSON, T.A. 1987. Heterosis and additive breed effects on feedlot and carcass traits from crossing Angus and Brown Swiss. J. Anim. Sci., 64(5):1332-39.

MOLETTA, J.L., RESTLE, J. 1996a. Influência do grupo genético sobre características qualitativas da carne de novilhos. R. Soc. Bras. Zootec., 26(5):866-875.

MOLETTA, J.L., RESTLE, J. 1996b. Características de carcaça de novilhos de diferentes grupos genéticos terminados em confinamento. R. Soc. Bras. Zootec., 26(5):877-888.

MORGAN, J.B., WHEELER, T.L., KOOHMARAIE, M. et al. 1993. Effect of castration on myofibrillar protein turnover, endogenous proteinase activities, and muscle growth in bovine skeletal muscle. J. Anim. Sci., 71(2):408-414.

MULLER, L. 1987. Normas para avaliação de carcaças e concurso de carcaça de novilhos. 2.ed. Santa Maria: UFSM. 31p.

MULLER, L., RESTLE, J. Carcass characterisitcs of steers and young bulls. In: EUROPEAN CONGRESS OF MEAT RESEARCHER WORKERS, 29, 1983, Parma. Proceedings... Parma: CERCA, 1983. p.530-535.

PEROBELLI, Z.V., MULLER, L., RESTLE, J. 1994. Estudo da qualidade das carcaças e da carne de vacas de descarte de dois grupos genéticos. Ciência Rural, 24(3):613-616.

RESTLE, J., FELTEN, H.G., VAZ, F.N. Efeito de raça e heterose para características quantitativas da carcaça de novilhos de 24 meses terminados em confinamento. In: REUNIÓN LATINOAMERICANA DE PRODUCCIÓN ANIMAL, 14, 1995, Mar del Plata. Memorias... Balcarce: ALPA, 1995a. p.857-859.

RESTLE, J., FELTEN, H.G., VAZ, F.N. et al. Efeito de raça e heterose para qualidade da carcaça e da carne de novilhos terminados em confinamento. In: REUNIÓN LATINOAMERICANA DE PRODUCCIÓN ANIMAL, 14, 1995, Mar del Plata. Memorias... Balcarce: ALPA, 1995b. p.854-856.

RESTLE, J., GRASSI, C., FEIJÓ, G.L.D. 1996a. Características das carcaças e da carne de bovinos inteiros ou submetidos a duas formas de castração, em condições de pastagem. R. Soc. Bras. Zootec., 25(2):334-344.

RESTLE, J., GRASSI, C., FEIJÓ, G.L.D. 1994. Características de carcaça de bovinos de corte inteiros ou castrados em diferentes idades. Pesq. Agrop. Bras., 29(10):1603-07.

RESTLE, J., KEPLIN, L.A.S., VAZ, F.N. 1997a. Características quantitativas da carcaça de novilhos Charolês, abatidos com diferentes pesos. Pesq. Agrop. Bras., 32(8):851-856.

RESTLE, J., KEPLIN, L.A.S., VAZ, F.N. et al. 1996b. Qualidade da carne de novilhos Charolês confinados e abatidos com diferentes pesos. Ciência Rural, 26(3):463-466.

RESTLE, J., ROCHA, J.B.T., FLORES, J.L.C. et al. Qualidade da carne de animais Hereford e suas cruzas com Nelore, abatidos aos quatorze meses. In: REUNIÃO ANUAL SOCIEDADE BRASILEIRA DE ZOOTECNIA, 34, 1997, Juiz de Fora. Anais... Juiz de Fora: SBZ, 1997b. p.196-198.

RESTLE, J., VAZ, F.N., ALVES FILHO, D.C. 1999. Machos não-castrados para a produção de carne. In: RESTLE, J. (Ed.) Confinamento, pastagens e suplementação para produção de bovinos de corte. Santa Maria: UFSM. p.215-231.

RESTLE, J., VAZ, F.N. 1997. Aspectos quantitativos da carcaça de machos Hereford inteiros ou castrados, abatidos aos quatorze meses. Pesq. Agrop. Bras., 32(10)1091-95.

RESTLE, J., VAZ, F.N. 1999. Confinamento de bovinos definidos e cruzados. In: LOBATO, J.F.P., BARCELLOS, J.O.J., KESSLER, A.M. (Eds.) Produção de bovinos de corte. Porto Alegre: EDIPUCRS. p.141-168.

ROCHA, J.B.T., PEROTTONI, J., RESTLE, J. et al. Qualidade da carne de animais inteiros de dois grupos genéticos, abati- 
dos aos quatorze meses de idade. In: REUNIÃO ANUAL SOCIEDADE BRASILEIRA DE ZOOTECNIA, 34, 1997, Juiz de Fora. Anais... Juiz de Fora: SBZ, 1997. p.199-201.

SAS, Institute Inc. 1990. SAS language reference. Version 6, Cary, NC: SAS Institute Inc. 1042p.

SEIDEMAN, S.C., CROSS, H.R., OLTJEN, R.R. et al. 1982. Utilization of the intact male for red meat production: a review. J. Anim. Sci., 55(4)826-840.

VAZ, F.N. Cruzamento alternado das raças Charolês e Nelore: características de carcaça e da carne de novilhos abatidos aos dois anos. Santa Maria, RS: UFSM, 1999, 58p. Dissertação (Mestrado em Zootecnia) - Universidade Federal de Santa Maria, 1999.

VAZ, F.N., RESTle, J., PEROTTONI, J. et al. Aspectos qualitativos da carcaça e da carne de machos Hereford, inteiros ou castrados, abatidos aos quatorze meses. In: REUNIÃO ANUAL SOCIEDADE BRASILEIRA DE ZOOTECNIA, 36, 1999, Porto Alegre. Anais... Porto Alegre: SBZ, 1999a. p.335.
VAZ, F.N., ROSO, C., VAZ, R.Z. 1999b. Gerenciamento visando a eficiência econômica da pecuária de corte. In: RESTLE, J. (Ed.) Confinamento, pastagens $e$ suplementação para produção de bovinos de corte. Santa Maria: UFSM. p.232-258.

WHEELER, T.L., CUNDIFF, L.V., KOCH, R.M. et al. 1996. Characterization of biological types of cattle (Cycle IV): carcass traits and longissimus palatability. J. Anim. Sci., 74(5):1023-35.

WHEELER, T.L., SAVELL, J.W., CROSS, H.R. et al. 1990. Mechanisms associated with the variation in tenderness of meat from Brahman and Hereford cattle. J. Anim. Sci., 68(12):4206-20.

Recebido em: 13/10/99

Aceito em: 30/10/00 